\title{
Emergency Department Pain Management and Its Impact On Patients' Short Term Outcome
}

\author{
Benedetta De Berardinis ${ }^{1, *}$, Laura Magrini ${ }^{1}$, Sara Calcinaro ${ }^{2}$, Luigi Mario Castello ${ }^{3}$, Gian Carlo \\ Avanzi $^{3}$, Andrea Semplicini ${ }^{4}$, Michele Alzetta ${ }^{4}$, Barbarella Giordano ${ }^{4}$ and Salvatore Di Somma ${ }^{1}$ \\ ${ }^{I}$ Emergency Department - Sant'Andrea Hospital, "Sapienza” University, Rome, Italy \\ ${ }^{2}$ Emergency Department - Agostino Gemelli Catholic University of the Sacred Heart Hospital, Rome, Italy \\ ${ }^{3}$ Emergency Department - Mayor of Charity Hospital of Novara, University of Eastern Piemont Amedeo Avogadro, Italy \\ ${ }^{4}$ Emergency Department - SS Giovanni e Paolo Hospital in Venice, University of Padua, Italy
}

\begin{abstract}
Background: Although pain is the most common complaint in the Emergency Department (ED), there is still a lack of adequate pain treatment by Emergency Physicians. Aim of this study was to describe pain management in ED from triage to discharge and to verify the effect of pain treatment in ED on a short term follow-up after discharge in order to evaluate patient's outcome.

Methods: A prospective multicentric study was conducted over two consecutive one week period in 4 ED teaching hospitals in Italy. All patients presenting with an acute, painful condition were eligible to participate in the study. The complete ED pain treatment was recorded, we enrolled 582 consecutive patients. One week after ED discharge a follow up evaluation through a phone call on patient's pain clinical condition was also obtained.

Results: There was a statistical significant difference between nurse and Emergency Physicians pain judgement $(\mathrm{p}<0.001)$. During ED visit: $54.2 \%$ received non steroid anti inflammatory drug (NSAID), $12.2 \%$ received paracetamol and $9.9 \%$ tramadol while morphine was used only in $5.6 \%$ of patients. Overall patient's satisfaction at one-week follow-up was as follows: in $63 \%$ of patients pain was completely absent, but on the other hand, $37 \%$ of patients had no pain relief, despite analgesic therapy prescription.

Conclusion: In our study we found differences between nurses and physicians judgments, they disagreed on the severity of pain. It was observed a low use of pain intensity scale with a formal measurement scales to assess pain. Our study demonstrates the importance of adequate ED and analgesic drug prescription for patients referring for pain in ED, and follow up assessment, many patients in follow up reported continued pain because of poor prescription of analgesic drug at discharge from ED. Improving analgesia in ED seems to be crucial for patients' quality of life and for preventing ED readmission for relapse of pain.
\end{abstract}

Keywords: Pain assessment, Emergency department, Pain intensity scales, Analgesia follow -up.

\section{INTRODUCTION}

Pain is the most common presenting complaint in the Emergency Department (ED) [1]. Many retrospective and prospective studies demonstrated that pain as patient's symptom is underestimated [1-6]. In a recent study timely and adequate treatment of pain has been demonstrated to be suboptimal, as $30 \%$ of patients reporting the same or more pain at time of discharge, and just over half rated their pain at discharge as moderate or severe [5]. Bonica et al., in a review of over 25,000 pages in 50 major textbooks covering

\footnotetext{
*Address correspondence to this author at the Emergency Medicine Department, Sant'Andrea Hospital, "Sapienza" Rome University - Emergency Medicine Postgraduate, School of Medicine and Psychology, Via di Grottarossa 1035-1039, 00189 Rome Italy; Tel: 0633775592; Fax: 0633775890; E-mail: benedetta.db@gmail.com
}

medicine, surgery, paediatrics, and emergency medicine, demonstrated that only 54 pages were addressed to the treatment of pain [7]. The lack of adequate pain treatment in ED has been well documented [8-13]. Inadequate research and options limitation for emergency physicians (EP) practice have been claimed as explanation [13]. Occasionally, a poor choice of analgesics, including a non-preferred route of administration, appears to alter the efficacy of acute pain treatment in the ED [9]. Gender, age, and ethnic biases have also been found to contribute to the lack of analgesic administration in the emergency setting [11], however undertreatment of pain was not confirmed to be associated with patient race or ethnicity [5]. Medical education has often been suggested as a mandatory way to improve the treatment of acute pain in ED [14]. This study was aimed to determine the management of pain from triage to discharge in patients referring to ED and to verify, by a short term follow up (1 
Table 1. Principal Diagnoses of Patients with Pain at ED Discharge

\begin{tabular}{|c|c|}
\hline & Total (582) \\
\hline \hline DIAGNOSIS & N (\%) \\
\hline TRAUMA & $259(44.5 \%)$ \\
\hline HEADACHE & $27(4.6 \%)$ \\
\hline NEURALGIA & $35(6.0 \%)$ \\
\hline OTORHINOLARYNGOLOGICAL & $12(2.0 \%)$ \\
\hline OPHTHALMOLOGICAL & $5(0.8 \%)$ \\
\hline ABDOMINAL & $114(19.5 \%)$ \\
\hline THORACIC & $56(9.6 \%)$ \\
\hline GYNECOLOGICAL & $14(2.4 \%)$ \\
\hline VASCULAR & $8(1.3 \%)$ \\
\hline NEPHRO-UROLOGICAL & $35(6.0 \%)$ \\
\hline NOT PERFORMED & $17(2.9 \%)$ \\
\hline
\end{tabular}

week), the efficacy of pain treatment in ED. A secondary objective has been to describe the current pain approach and treatment in four Italian teaching EDs, from triage to discharge, and to quantify the effective use of intensity pain scales.

\section{MATERIALS AND METHODOLOGY}

This was a multicenter prospective observational clinical study conducted in the ED of four teaching hospitals in Italy (Sant'Andrea Hospital in Rome - coordinating center -, Agostino Gemelli Catholic University of the Sacred Heart Hospital in Rome, University Mayor of Charity Hospital of Novara and SS. Giovanni e Paolo Hospital in Venice) and in which 582 patients were enrolled. The protocol was approved by the ethical committee of each participating hospital. Written informed consent was obtained from each patient prior to enrolment.

Inclusion criteria: We enrolled all patients who arrived in the ED complaining pain in a free two week period in 2011 (first two weeks of June).

Exclusion criteria: age less than 18, and patients unable to fill the informed consent.

Triage urgency level was established by a trained triage nurse on a four point acuity scale on the basis of the global triage model proposed from the "Gruppo Formazione Triage" (GFT) [15]. Triage level acuity was classified into 3 groups: Level 1 or Red code (emergent/resuscitation), Level 2 or Yellow code (urgent), Level 3 or Green code (semiurgent). In Level 1 patient has critical conditions with a compromise of a vital function; in Level 2 patient has conditions that are potentially life-threatening or alterations of limb or sense function without compromise of a vital function; in Level 3 patient has conditions that should be evaluated by a physician, and might deteriorate or benefit from medical intervention but without potential threats to life or limb or sense function. On the basis of this classification Level 1 and 2 have rapid access in the ED emergency area and the physician's examination is immediate in the first case and into few minutes in the second one, while, for the Level 3, expected waiting times are more prolonged. The model proposed from the GFT has been adopted by each Italian region included Lazio, Piemonte, Veneto and has been imposed on every ED of the Italian regions on the basis of the Guidelines for the Organization of the Emergency Network in Italy created by the Act of Agreement Conference State-Regions/Ministry of Health (D.P.R. 27/03/92) [16].

Anamnestic data and demographic information were recorded. Data for each patient enrolled in the study were collected in Case Report Form (CRF). CRF contained all the information about pain: onset, duration, how the triage nurse judged it (absent, moderate, severe or more severe), priority code assigned, and, if any, pain intensity scale score, once EP assessed patient's pain (absent, moderate, severe or more severe), through two graduated pain intensity scales: the Visual Analogue Scale (VAS) and the verbal Numerical Rating Scale (NRS). The first, VAS, is a measurement instrument represented by a horizontal line, $100 \mathrm{~mm}$ in length, anchored by word descriptors at each end (absent and the worst pain). The patient marks on the line the point that he feels represents his perception of pain. The VAS score is determined by measuring in millimetres from the left hand end of the line to the point that the patient marks. The second scale, NRS, is a 11,21 or 101 point scale where the end points are the extremes of no pain and worst pain. The NRS can be graphically or verbally delivered [17].

Data regarding pain localization (trauma, abdomen, chest, neurologic apparatus, gynaecologic apparatus, vessels, eye and otorhinolaryngeal) were also recorded. The pain was characterized by EP interview, with a specific question about the onset, localization, site, duration and the quality of pain. CRF contained also patient's final disposition (discharged, hospitalized, transferred in other hospitals, stay in short observation units) and analgesic therapy prescription (type of drug, dosage, way of administration). On the basis of anamnestic data and physical examination the EP decided to administrate analgesic therapy at different levels of dosage in consideration of the intensity of pain.

One week later discharge, a phone call follow-up was performed, by mean of a dedicated questionnaire aimed to know patient conditions, whether pain was present or absent, or the severity pain's degree, and analgesic therapy efficacy. Those patients admitted to hospital or in observation unit were not included in the phone call follow up. Residents performed phone call using standardized questions and they were not blinded to ED treatment.

\section{STATISTICAL ANALISYS}

Discrete variables were expressed in percentage; for normally distributed data, continuous variables were presented as mean \pm standard deviation (SD) and statistical significance was assessed by $\mathrm{T}$ test, otherwise, a non parametric test, the Wilcoxon rank sum test was employed if appropriate. The statistical significance of the association between dichotomous variables was assessed by the Fisher exact test 


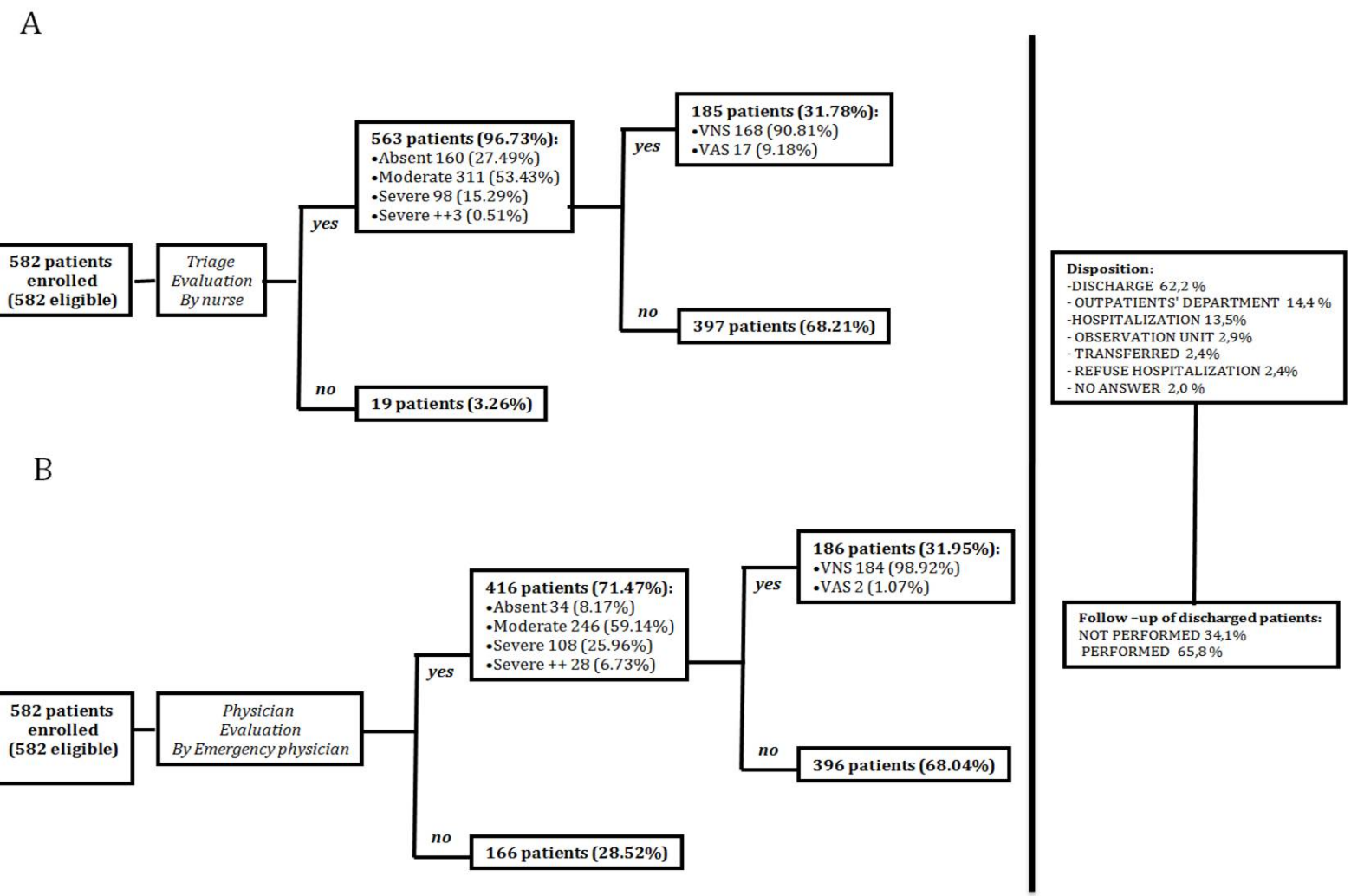

Fig. (1A-B). Study Algorithms.

Table 2. Nurse at Triage and Emergency Physician During ED Visit Pain Judgement and Follow Up

\begin{tabular}{|c|c|c|c|c|}
\hline \multicolumn{2}{|c|}{ Pain Judgement } & Severe (\%) & Very Severe (\%) \\
\hline \hline Nurse at triage & Absent (\%) & Moderate (\%) & $15.2^{\#}$ & $0.5^{\S}$ \\
\hline Physician at ED visit & $27.4^{*}$ & 53.4 & $25.9^{\#}$ & $6.7^{\S}$ \\
\hline Follow - up & $8.7^{*}$ & 61.5 & 6.2 & $0.7^{\S}$ \\
\hline
\end{tabular}

${ }_{\mathrm{p}}^{\mathrm{p}}<0.001,{ }^{\sharp} \mathrm{p}<0.007,{ }^{\S} \mathrm{p}<0.004$

and significance of results was determined using $\chi^{2}$ analysis. The threshold for statistical significance was $\alpha<0.05$. We used Medcalc (Medcalc, Mariakerke, Belgium) software version 12.1.4.

\section{RESULTS}

We enrolled 582 patients. 287 (49\%) were men, with mean age of $49 \pm 19$ years. At nurse triage pain evaluation: $19(3.2 \%)$ patients have not been judged at all while in the others (563) pain was judged as: absent in $160(27.4 \%)$, moderate in $311(53.4 \%)$, severe in $89(15.2 \%)$, and very severe in $3(0.5 \%)$. ED pain nurse scale assessment was performed in only $185 / 582(31.7 \%)$ patients. VAS was performed in $17(9.1 \%)$ and NRS in $168(90.8 \%)$ of them, while in $397(68.2 \%)$ patients the pain scale assessment was not performed (Fig. 1A).
During EP's visit pain was evaluated again in 416 patients $(71.4 \%$ of total enrolled patients) and it was reassessed as: absent in $34(8.1 \%)$ of patients, moderate in $246(59.1 \%)$, severe in $108(25.9 \%)$ and very severe in $28(6.7 \%)$ of patients Table 2 . Intensity pain scale scores were obtained in 186/582 (31.9\%) patients: VAS has been used in $2(1.0 \%)$ and NRS in $184(98.9 \%)$ (Fig. 1B). 166 patients were not evaluated by the EP because of the severity of primary disease that was the cause of their access in ED and that did not allow to waste time in interviewing, in fact, in these cases the EP had to act immediately for life-threatening conditions of patients. There was a statistical significant difference between nurse and EP pain judgement, by using the pain score scales, in absent and very severe pain (respectively $\mathrm{p}<0.001$ and $\mathrm{p}<0.007)($ Table 2). During the EP visit analgesic drugs were administered in 212 patients $(36.4 \%)$. In the patients' group who received a pain medication, $54.2 \%$ received a non steroidal anti inflammatory drug (NSAID), $12.2 \%$ paraceta- 
Table 3. A-B. Drug Administered During Emergency Physician Visit and Discharge

\begin{tabular}{|c|c|c|}
\hline Drug Administered During Emergency Physician Visit & $\mathbf{N}$ & $\%$ \\
\hline NSAID (IV) & 115 & 54,2 \\
\hline PARACETAMOL (IV) & 26 & 12,2 \\
\hline TRAMADOL (IV) & 21 & 9,9 \\
\hline CODEINE+PARACETAMOL (PO) & 6 & 2,8 \\
\hline MORPHINE (IV) & 1 & 0,4 \\
\hline OTHER & 29 & 13,6 \\
\hline NSAID+TRAMADOL (IV) & 4 & 1,8 \\
\hline NSAID+PARACETAMOL (IV) & 5 & 2,3 \\
\hline NSAID+MORPHINE (IV) & 2 & 0,9 \\
\hline NSAID+TRAMADOL+MORPHINE (IV) & 2 & 0,9 \\
\hline TRAMADOL+ MORPHINE (IV) & 1 & 0,4 \\
\hline Drug Administered at Discharge & $\mathbf{N}$ & $\%$ \\
\hline NSAID (PO) & 140 & 47,4 \\
\hline PARACETAMOL (PO) & 51 & 17,2 \\
\hline TRAMADOL (PO) & 10 & 3,3 \\
\hline CODEINE+PARACETAMOL (PO) & 52 & 17,6 \\
\hline MORPHINE (PO) & 0 & 0 \\
\hline OTHER (PO) & 32 & 10,8 \\
\hline NSAID+TRAMADOL (PO) & 1 & 0,3 \\
\hline NSAID+PARACETAMOL (PO) & 5 & 1,6 \\
\hline NSAID+MORPHINE (PO) & 0 & 0 \\
\hline NSAID+TRAMADOL+MORPHINE (PO) & 4 & 1,3 \\
\hline TRAMADOL+ MORPHINE (PO) & 0 & 0 \\
\hline
\end{tabular}

(PO): per oral, (IV): Intravenous

mol, $9.9 \%$ tramadol, $4.7 \%$ opioids and $0.9 \%$ opioids and NSAID (in each comparison of NSAID versus each of the other drugs there is a statistical difference, $\mathrm{p}<0.0001)$. A parenteral medication was given to $80.6 \%$ of patients, and the most frequent administrated drug was Ketorolac $(41.3 \%)$ (Table 3A). After ED visit 458 (78.6\%) patients were discharged at home, 107 (15.9\%) hospitalized, 17 $(2.9 \%)$ stayed in observation unit.

The reasons of pain are expressed in Table $\mathbf{1}$. The analgesic medications were prescribed in only $50.6 \%$ of discharged patients. Table 3A,B shows the percentage of drug prescribed at home for pain relief. All drugs prescribed were oral pills or tablets.

Follow-up: Of discharged patients $83.8 \%$ were followed up one week later, $16.2 \%$ of patients, that were hospitalized or did not answer to the phone call, did not participate to follow-up. No significant difference between patients who completed the follow up and those who did not, according to age, sex, pain at presentation or discharge was observed.
During phone call follow-up interview the patients' pain perception was described (Table 2). In 240 (49,2\%) patients, one week later, there was a statistical difference for pain absent $(p<0.001)$, severe and very severe (respectively $\mathrm{p}<0.004$ and $\mathrm{p}<0.007$ ). The use of prescription did not provide pain relief when pain at follow-up was compared to pain at discharge. More importantly in $37 \%$ of patients pain was still present.

\section{DISCUSSION}

It is well known that pain evaluation at ED arrival is very important in order to allow priority code assessment, time to treatment and the right final diagnosis. Therefore, the intensity of pain should be considered as a vital sign as like Temperature, Blood Pressure, Heart Rate, Respiratory Rate and Oxygen Saturation. The pain assessment in the Triage should become the sixth vital sign, monitored and assessed from the triage to EP visit. In our study the pain scales were used both by nurses and physicians, in particular the results showed 
that in most cases the NRS was used $[18,19]$. The probability for the EP to prescribe medication for pain was directly related to increasing scores of pain scales, that is, the higher was the score of pain scales, and the more probably drugs were administered. Methods relying on the physician's assessment of pain are inadequate because patients are ultimately the only true experts in evaluating the intensity of their own pain. For this reason, in the recent years have been created several scales of pain in order to facilitate the understanding, by the physician, of the patient's pain intensity. The major global or one-dimensional scales used with adult patients are NRS and the VAS [20]. These scales have been evaluated for chronic and acute postoperative, obstetric, or dental pain [21]. Their simplicity and rapidity of use and their sensitivity in terms of discriminating the strength of pain intensity make them suitable tools for evaluating acute pain in ED patients [22, 23]. Their repeated use in successive tests may be indicative of the efficacy of analgesic treatment. No method has been proposed in the literature for use in routine clinical practice [22-24]. Our study demonstrates that there exists a discrepancy of scale pain assessment between nurses and ED physicians. In fact nurse judged pain as: "absent", was present in a higher percentage of patients in comparison to physician's evaluation $(27.4 \%$ vs $8.1 \%)$. On the contrary in our study it occurred that nurse judged pain as "very severe", was present in a lower percentage of patients compared to EP $(0.5 \%$ vs $6.7 \%)$.

Oral and parenteral medications were used in $36.4 \%$ of patients, of these $82.0 \%$ received oral medications, and $80.6 \%$ parenteral drugs. These percentages are justified by the fact that frequently, most patients receiving oral medications did not achieved a valuable analgesia, and an adjunctive parenteral drug could be necessary. The most commonly used intravenous drug was ketorolac, a NSAID (41.3\%). Morphine-derived (codeine) drugs were used orally, and not intravenous even if it is well known that morphine is considered the best strategy of analgesia for severe pain [25]. The underuse of morphine in ED is known [26], and it is mainly due to the fear of side effects, different habits of EP regarding the use of opioids, the opiophobia.

In Italy in March $15^{\text {th }} 2010$ the law number 38 that includes "Provisions to ensure access to palliative care and pain therapy" has been approved [27]. This law requires of reporting the detection of pain in the medical record, of training and refreshing of physicians and nurses and the simplification of procedure to access to analgesic drugs used for pain relief therapy [27].

Physician's perceptions regarding analgesic therapy, and lack of physician training from the recognition of inadequate pain management to the application of various available treatment modalities are factors that can contribute to inadequate pain management. In the past, medical schools and postgraduate training programs have not placed a substantial educational emphasis on pain management [28], and this has contributed to many physicians' negative attitudes about opioids and a reluctance to prescribe them [28, 29]. An high proportion of physicians expressed fear of drug addiction as a reason against the use of opioid analgesics-, approximately $28 \%$, believed that patients receiving opioids for pain relief were at significant risk for addiction, and an even greater proportion of physicians $(39 \%)$ were concerned about addiction if a family member had to be prescribed morphine [29]. While opioids remain the foundation of pain management for moderate to severe pain, the use of multiple analgesics with different mechanisms of action has shown increasing promise in clinical practice. A multimodal approach could provide significant benefits including reduction in pain intensity, optimal opioid dose, and reduced opioid-related adverse events [30]. Several clinical studies documented not only the ability of this approach to provide better pain relief with a reduced consumption of opioids and/or superior tolerability/side effects profile, but also the potential to lower the incidence of chronic pain development [30]. A shift in the pain treatment paradigm is supported by practice guidelines from the American Society of Anesthesiologists Task Force on Acute Pain Management [31].

In Unites States the prescription of opioids abuse has become, recently, a major public health problem, but this is not in Italy where there is still by the EP awe in pain control through the routine use of opioids. But EP must absolutely provide appropriate pain control for patients discharged from ED without contributing to the public health concerns associated with opioids prescription. It could be expectable that a closely integrated primary and specialty care, providing by the EP limited opioid analgesia, should be part of the discharge planning not only in Italy but in all the world.

In our study patients' characteristics were similar in consideration of age and sex, and this is relevant because there is a different sensation of pain in consideration of aging and of diseases. In the elderly there is an higher threshold of pain and it is well known in the diabetes the pain is altered by neuropathy [32]. This result is important because it permits to underline the relevance of assessing and of monitoring pain from the beginning of patient's ED stay. From our results it can be noted that in the consideration of severity levels of pain there is a difference between physician and nurse judgment. The difference is statistically significant for the absence of pain and, especially, of the very severe pain.

From our data the most frequent final disposition was discharge in $78.6 \%$ of cases, and only $15.9 \%$ of patients were hospitalized in relation to the cause of pain (mainly trauma). In those discharged, analgesic drugs were prescribed in almost $51 \%$ of patients.

At follow up evaluation the most relevant evidence was that only the $62.6 \%$ of patients described their pain as completely disappeared. This percentage reflects the difficulties to completely control pain at discharge, probably related, again, to the underestimation of pain by nurses and by ED physicians, but also to the inadequate pain management during the visits in ED probably due to the underuse of morphine. In our opinion the persistence of pain at follow up is probably linked to misuse of opioids. Our study underlines the importance of follow up that allows to point out still the presence of pain in almost $40 \%$ of patients.

This study highlights the issue of oligoanalgesia among ED patients presenting with pain-related complaints. Oligoanalgesia problem has two natures: one is due to the patients' refuse to receive analgesics. The second one is probably related to the physician's perceptions regarding analgesic 
therapy and lack of physician's training in the specific area of the recognition of pain, and, subsequently, of inadequate pain management [33]. The patient's satisfaction about pain relief was influenced by effectiveness of medication, independently of pain intensity, and by communication with the physician and with nurses. No recent data in the literature were published about the importance of pain assessment in ED or describing the correct approach during EP visit and evaluating the follow up outcome. Implications for nursing practice include a need for assessment of patients' pain intensity, the development of pain management protocols, and increased emphasis on education in both undergraduate and postgraduate nursing curricula. Also there seems to be a need for continued clinical audit of pain management standards for EP and nurses.

The limitations of our study were a relatively low contact for follow-up, and consequently loss of information, lack of blinding for the treatment by the providers, lack of subgroup analysis (elderly), lack of uniform criteria for analgesic selection by EP due probably to personal practice and experience.

\section{CONCLUSIONS}

In summary, there is still a need for improving assessment on pain management in ED. Of great importance seems the need to perform a follow up for patients referring to the ED for pain. This should improve physicians' attitudes about opioids use and a less reluctance to prescribe them. Patients discharged from ED reported high satisfaction when an analgesic treatment was recommended at home. Our study demonstrates the importance of pain management in ED and after ED discharge since this can result in ameliorating patients' quality of life and to prevent consequentially pain relapse and ED readmissions with subsequent overcrowding in ED by patients who, in alternative, could be safely visited also in out clinics. This study also seems to underline the low use of opioids during ED stay and consequent persistency of pain.

\section{LIST OF ABBREVATIONS}

$\begin{array}{ll}\text { ED } & =\text { Emergency Department } \\ \mathrm{EP} & =\text { Emergency Physicians } \\ \mathrm{GFT} & =\text { Gruppo Formazione Triage } \\ \mathrm{CRF} & =\text { Case Report Form } \\ \text { VAS } & =\text { Visual Analogue Scale } \\ \text { NRS } & =\text { Numerical Rating Scale } \\ \mathrm{SD} & =\text { Standard Deviation } \\ \text { NSAID } & =\text { Non Steroidal Anti Inflammatory Drug }\end{array}$

\section{CONFLICT OF INTEREST}

No Grants and no sources of support have been received for the study. All authors have no conflicts to report.

\section{AKNOWLEDGEMENTS}

We thank Angelini Pharma for their help in design of the study.

\section{REFERENCES}

[1] Cordell WH, Keene KK, Giles BK, Jones JB, Jones JH, Brizendine EJ. The high prevalence of pain in emergency medical care. Am J Emerg Med 2002; 20: 165-9.

[2] Selbst SM, Clark M. Analgesic use in the emergency department. Ann Emerg Med 1990; 19: 1010-3.

[3] Wilson JE, Pendleton JM. Oligoanalgesia in the emergency department. Am J Emerg Med 1989; 7: 620-3.

[4] Reichl M, Bodiwala GG. Use of analgesia in severe pain in the accident and emergency department. Arch Emerg Med 1987; 4: 2531.

[5] Bijur P, Berard A, Esses D, Calderon Y, Gallagher EJ. Race, ethnicity, and management of pain from longbone fractures: A prospective study of two academic urban emergency departments. Acad Emerg Med 2008; 15: 589-97.

[6] Todd KH, Sloan EP, Chen C, Eder S, Wamstad K. Survey of pain etiology, management practices and patient satisfaction in two urban emergency departments. CJEM 2002; 4: 252-6.

[7] Bonica JJ. Biology, pathophysiology, and treatment of acute pain. In: Lipton S, Ed. Persistent pain: modern methods of treatment, 1985 Chapter 1. (Grune Stratton).

[8] Ducharme J, Barber C. A prospective blinded study on emergency pain assessment and therapy. J Emerg Med 1995; 13: 571-5.

[9] Todd KH, Ducharme J, Choiniere M, et al. PEMI Study Group. Pain in the emergency department: Results of the pain and emergency medicine initiative (PEMI) multicenter study. J Pain 2007; 8:460-6.

[10] Ducharme J. Emergency pain management: A Canadian Association of Emergency Physicians (CAEP) consensus document. J Emerg Med 1994; 12: 855-66.

[11] Pletcher MJ, Kertesz SG, Kohn MA, Gonzales R. Trends in opioid prescribing by race/ethnicity for patients seeking care in US emergency departments. JAMA 2008; 299: 70-8.

[12] Ducharme J. Proceedings from the first international symposium on pain research in emergency medicine: Foreword. Ann Emerg Med 1996; 27: 399-403.

[13] American College of Emergency Physicians Board of Directors: Policy Statement. Pain management in the emergency department. Ann Emerg Med 2004; 44: 198.

[14] Ducharme J. Acute pain and pain control: State of the art. Ann Emerg Med 2000; 35: 592-603.

[15] Gruppo Formazione Triage. Triage Infermieristico. Milano: Mc Graw - Hill. 2006

[16] Il Triage Ospedaliero. Gruppo Triage Lazio. Agenzia di Sanità Pubblica. Roma 2007. Available at: [http://www.asplazio.it/]

[17] Williamson A, Hoggart B. Pain: a review of three commonly used pain rating scales. J Clin Nursing 2005; 14(7): 798-804.

[18] Holdgate A, Asha S, Craig J, Thompson J. Comparison of a verbal numeric rating scale with the visual analogue scale for the measurement of acute pain. Emerg Med 2003; 15: 441-6.

[19] Marquie L, Duarte LR, Marine C, Lauque D, Sorum PC. How patients and physicians rate patients' pain in a French emergency department using a verbally administered numerical rating scale and a visual analog scale. Acute Pain 2008; 10: 31-7.

[20] Sriwatanakul K, Kelvie W, Lasagna L, Calimlim JF, Weis OF, Mehta G. Studies with different types of visual analogue scales for measurement of pain. Clin Pharmacol Ther 1983; 34: 234-9.

[21] Berthier F, Potel G, Leconte P, Touze MD, Baron D. Comparative Study of Methods of Measuring Acute Pain Intensity in ED. Am J Emerg Med 1998; 16: 132-136.

[22] Hjermstad MJ, Fayers PM, Haugen DF, et al. European Palliative Care Research Collaborative (EPCRC). Studies comparing Numerical Rating Scales, Verbal Rating Scales, and Visual Analogue Scales for assessment of pain intensity in adults: a systematic literature review. J Pain Symptom Manage 2011; 41:1073-93. Review.

[23] Daoust R, Beaulieu P, Manzini C, Chauny JM, Lavigne G. Estimation of pain intensity in emergency medicine: a validation study. Pain 2008; 138: 565-70.

[24] Todd KH. Pain assessment instruments for use in the emergency department. Emerg Med Clin North Am 2005; 23: 285-95.

[25] Bijur PE, Kenny MK, Gallagher EJ. Intravenous morphine at 0.1 $\mathrm{mg} / \mathrm{kg}$ is not effective for controlling severe acute pain in the majority of patients. Ann Emerg Med 2005; 46:362-7. 
[26] Gueant S, Taleb A, Borel-Kuhner J, et al. Quality of pain management in the emergency department: results of a multicenter prospective study. Eur J Anesthesiol 2011; 28: 97-105.

[27] Legge. 15 Marzo Gazzetta Ufficiale n 65 del 19 Marzo 2010. Available from: http://www.parlamento.it/par-lam/leggi/100381.htm

[28] Rupp T, Delaney KA. Inadequate analgesia in emergency medicine. Ann Emerg Med 2004; 43: 494-503.

[29] Weinstein SM, Laux LF, Thornby JI, et al. Physicians' attitudes toward pain and the use of opioid analgesics: Results of a survey from the Texas Cancer Pain Initiative. South Med J 2000; 93: 47987.
[30] Sinatra R. Causes and Consequences of Inadequate Management of Acute Pain. Rev Pain Med 2010; 11:1859-71.

[31] Practice guidelines for acute pain management in the perioperative setting. An updated report by the American Society of Anesthesiologists Task Force on Acute Pain Management. Anesthesiology 2004; 100:1573-81.

[32] Jones JS, Johson K, McNinch M. Age as a risk factor for inadequate emergency department analgesia. Am J Emerg Med 2003; 21: 461-6.

[33] Hwang U, Richardson LD, Sonuyi TO, Morrison RS. The effect of emergency department crowding on the management of pain in older adults with hip fracture. J Am Geriatr Soc 2006; 54: 270-5.

De Berardinis et al.; Licensee Bentham Open.

This is an open access article licensed under the terms of the Creative Commons Attribution Non-Commercial License (http://creativecommons.org/licenses/ by-nc/3.0/) which permits unrestricted, non-commercial use, distribution and reproduction in any medium, provided the work is properly cited. 